\begin{tabular}{|l|l|}
\hline $\begin{array}{l}\text { El Mercosur como proceso multidimensional y cómo estudiarlo desde las ciencias } \\
\text { sociales }\end{array}$ & Titulo \\
\hline de Sierra, Gerónimo - Autor/a & Autor(es) \\
\hline Los rostros del Mercosur. El difícil camino de lo comercial a lo societal & En: \\
\hline Buenos Aires & Lugar \\
\hline CLACSO, Consejo Latinoamericano de Ciencias Sociales & Editorial/Editor \\
\hline 2001 & Fecha \\
\hline & Colección \\
\hline $\begin{array}{l}\text { Modelos de Crecimiento; Mercados comunes; Integracion economica; Integracion } \\
\text { Regional; Ciencias sociales; Brasil; Argentina; Mercosur, Mercado Comun del Sur; } \\
\text { Paraguay; Uruguay ; }\end{array}$ & Temas \\
\hline Capítulo de Libro & Tipo de documento \\
\hline http://bibliotecavirtual.clacso.org.ar/clacso/gt/20101026061047/2sierra.pdf & URL \\
\hline $\begin{array}{l}\text { Reconocimiento-No comercial-Sin obras derivadas 2.0 Genérica } \\
\text { http://creativecommons.org/licenses/by-nc-nd/2.0/deed.es }\end{array}$ & Licencia \\
\hline
\end{tabular}

Segui buscando en la Red de Bibliotecas Virtuales de CLACSO http://biblioteca.clacso.edu.ar

Consejo Latinoamericano de Ciencias Sociales (CLACSO)

Conselho Latino-americano de Ciências Sociais (CLACSO)

Latin American Council of Social Sciences (CLACSO)

www.clacso.edu.ar

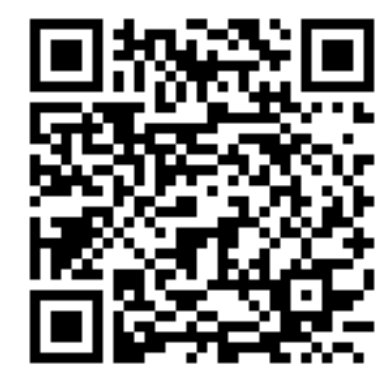




\title{
El M ercosur como proceso multidimensional y cómo estudiarlo desde las ciencias sociales
}

\author{
$\approx$ Gerónimo de Sierra*
}

$\mathrm{E}$ 1 Mercosur -tal como busca expresarlo el título del libro- es un proceso en plena evolución. Estudiarlo supone pues confrontarse con algo que está su cediendo, y como bien se sabe, en ciencias sociales esa es una tarea siempre compleja y llena de escollos imprevistos. Por otra parte, los cientistas sociales -aún en el caso de estar provistos de los mejores instrumentos conceptuales, y la mejor información disponible- no pueden ni deben sentirse pitonisos y pretender predecir el futuro. La multiplicidad de dimensiones y variables que inciden en un proceso social, si se lo aborda en toda su complejidad, obligan siempre a la modestia. Más aún cuando estamos frente a un proceso de integración entre países/sociedades de la magnitud territorial, demográfica y sociocultural como el que involucra al Mercosur.

Los trabajos que se recogen en este volumen son, por un lado, una expresión parcial -aunque plural y multidisciplinaria- de los diversos esfuerzos de investigación que hoy se realizan sobre el tema Mercosur; y por otro lado un intento, programado, de superar una cierta tendencia de facto a reducir su análisis a enfoques reduccionistas - por unidimensionales- de diverso tipo; no pocas veces focalizando sólo las dimensiones económicas o -lo que es aún peor- sólo su dimensión comercial.

Puede decirse que en importante medida, el carácter multidimensional de la verdadera revolución que en varios planos implica el proceso en curso es subva-

"Profesor-Investigador en grado y posgrado de Sociología en la Universidad de la República-Uruguay; Coordinador del Grupo de Trabajo de CLACSO sobre "Mercosur e Integración"; miembro del Comité Directivo de CLACSO. 
lorado no sólo por los ciudadanos de cada país sino también por los analistas, los políticos y los actores sociales. Ello es en parte "lógico", o esperable, pero al ser los enfoques unidimensionales una perspectiva errónea por su carácter limitante, los mismos deben ser criticados metodológicamente; y al mismo tiempo se debe construir los conceptos, y recoger y analizar los datos empíricos, que ayuden a superar poco a poco los reduccionismos que dificultan una comprensión acabada de lo que está sucediendo; así como también se debe diseñar los escenarios alternativos y sus probabilidades diferenciales. La modestia metodológica referida anteriormente no implica pues sumisión a la pura descripción fáctica, o al predominio de los análisis exclusivamente "económicos" o "jurídicos" en el estudio del proceso mercosuriano. En general nadie defiende teóricamente este reduccionismo, pero en la práctica tiende a imponerse como algo natural. Las causas de esto son diversas, pero sin duda pesan dos hechos "duros" y difíciles de superar: por un lado el indiscutible peso estratégico de los procesos económicos, así como la mayor disponibilidad de información pública y privada sobre los aspectos económicos y sobre todo comerciales del Mercosur; por el otro, la gran capacidad de lobby comunicacional de los actores económicos y técnico-económicos más activos en el proceso, que en su gran mayoría son instancias gubernamentales o grandes grupos empresariales, ya sea nacionales o transnacionales.

Frente a esta realidad, el esfuerzo anti-reduccionista que nos propusimos en este libro está lejos de ser una reivindicación estrecha de las "otras" ciencias sociales. En realidad parte de un intento de objetividad científica por reconocer no solamente lo obvio -los complejos aspectos culturales, identitarios, sociales, laborales, educativos, políticos, etc. que están involucrados de hecho en este procesosino una constatación contundente y casi preliminar: ni los acuerdos "estatales" de Asunción, Ouro Preto y posteriores, ni los impactantes avances en el comercio y las inversiones intrarregionales de este decenio, habrían existido o sobrevivido sin una conjunción -sin duda fluctuante y con altibajos- de voluntades políticas en sentido estricto. Es cierto que se trató, en primer lugar, de decisiones políticas cupulares al más alto nivel estatal; pero como bien han mostrado hace mucho la ciencia política y la sociología política, quien dice estatal está suponiendo "detrás" un amplio, complejo y estratificado entramado de actores sociales que les dan sustento y hacen posible la toma de decisiones a nivel de la cúpula gubernamental. Lo contrario sería suponer que el simple arbitrio o la casual convergencia de múltiples y heterogéneos gobiernos -como los que se sucedieron en estos diez años en los cuatro países - pudieran dar cuenta de la relativa continuidad de esta suerte de revolución geopolítica que representa el Mercosur para la región.

O sea que legitimar y fundamentar un análisis multidisciplinario y multidimensional del proceso en curso es al mismo tiempo no sólo ayudar a comprender lo sucedido, sino una forma de contribuir a un mejor diagnóstico de los vaivenes y dificultades que tuvo y tiene por delante una eventual culminación "exitosa" del ambicioso proyecto que se puso en marcha con el tratado de Asunción. Efectiva- 
mente, no es adecuado soslayar que desde el inicio han convivido -y aún hoy conviven- en los cuatro países, y fuera de ellos, posiciones claramente encontradas sobre el perfil del acuerdo a llevar adelante; incluso si nos restringimos al universo de las cúpulas político-técnicas del estado y empresariales.

Estas posiciones divergentes no deben sorprender. Así ha sucedido antes, no sólo en el caso a menudo tomado como referencia de la Unión Europea, sino en todos los grandes virajes del formato de desarrollo e inserción internacional que han adoptado nuestros países desde su independencia. Pero así como actualmente se acepta pacíficamente como clásicos a enfoques multidimensionales para etapas pasadas del continente ${ }^{2}$, debemos hoy defender y enriquecer creativamente ese legado, y mostrar cómo múltiples niveles y actores de la sociedad de los cuatro países se ven involucrados e interactúan, aunque en grado y fuerza distinta, en el proceso en curso. Para que este enfoque sea fecundo, es necesario justamente desagregar y estudiar en su especificidad no sólo los intercambios comerciales o la economía política de la región y de cada país, sino también la estructura social y de clases, el sistema político y de partidos, el formato estatal, los movimientos sociales, el grado de desarrollo material y de equidad social, la profesionalidad y creatividad de las elites estatales y de la sociedad civil, la configuración del sistema de actores sociales, los modelos culturales y el imaginario colectivo, así como varios otros aspectos, incluyendo naturalmente la nueva realidad mundial.

También aparece como relevante para un análisis del proceso desde las ciencias sociales, la superación de aquellos enfoques bastante en boga actualmente que toman al Mercosur como un dato, no sólo fáctico, sino conceptualmente casi exógeno a las sociedades involucradas; y que desde ese punto de partida pasan luego a analizar cómo reaccionan o se adaptan a dicho fenómeno los distintos actores y subsistemas sociales. Sin negar la utilidad de estos trabajos, creemos que también debe superarse -por insuficiente- su supuesto implícito de que, dado que el Mercosur "ya está ahî", lo que importa es ver qué efectos tiene sobre los diversos actores y estructuras preexistentes en cada país.

Se trata de un dilema clásico de los análisis del cambio social, inevitablemente involucrados en la tensión diacronía-sincronía (y estructuras-actores). En los cincuenta y los sesenta, las ciencias sociales en América Latina ya vivieron esa discusión, que es propiamente teórica y metodológica, por más que habitualmente se tiña también de presupuestos ideológicos o propiamente políticos. En aquella ocasión se trataba de dar cuenta de los acelerados procesos de modernización y movilización, ligados a la industrialización y al habitualmente llamado "crecimiento hacia adentro". Los enfoques de Costa Pinto, Heintz y Germani por un lado, y de Touraine, Nun y Cardoso por otro - para nombrar sólo a algunos exponentes relevantes de aquel debate- representaron en buena medida los dos polos de esa dicotomía.

Si bien desde entonces los países "centrales" y la región han cambiado mucho -así como la estructura de sus relaciones mutuas-, su formato sigue siendo de in - 
teracción asimétrica con nuevas formas de dependencia, aunque es cierto que con nuevas reglas de juego, en cierta medida aún más rudas y exigentes en el caso de tres de los países que integran el Mercosur. Pero más allá de la frecuentemente sostenida "exterioridad" del Mercosur cuando se lo analiza en tanto fenómeno político-institucional involucrando "países" (enfoque sin duda empíricamente insuficiente), ahora nos interesa relevar brevemente otros dos supuestos que suelen sustentar el enfoque que estamos criticando: la idea de que la revolución tecnológicoproductiva haría "inevitable" el formato Mercosur para la región; y el supuesto de que "el Mercosur está ahî" y lo que cabe es estudiar sus efectos.

El primer defecto de estos enfoques radica en el plano fáctico o de los hechos históricos. Como dijimos más arriba, es el propio formato y contenido del llamado Mercosur el que estuvo y está en "disputa" (y muy limitado sería querer estudiar sólo efectos de su presencia). En disputa no sólo en el continuo que va de la simple Zona de Libre Comercio a un verdadero Mercado Común (al límite con su propia moneda regional única y todas sus implicancias), sino en cuanto a si el acuerdo de integración debe limitarse a los aspectos comerciales y económicos, o por el contrario, si debe constituirse en un pacto de integración productiva, social, política, geopolítica y cultural, que involucre a toda la sociedad y no sólo a los empresarios, especialmente a los que "exportan" bienes transables3.

Es el propio Mercosur, como tal, que debe ser analizado como un proceso abierto y en formación. Y por otra parte es necesario reconocer que más allá de las indudables presiones de las nuevas condiciones técnicas de producción hacia la conformación de mercados amplios (¿mundiales?, ¿regionales?) ${ }^{4}$, fue y es el estado de las relaciones de fuerza en el mercado y las conexiones políticas y tecnoburocráticas de los actores sociales y sobre todo económicos, lo que fue pautando la trama de las sucesivas decisiones concretas de los gobiernos. De otro modo no se entendería que los Estados Unidos y la propia cúpula de la Organización Mundial del Comercio continúen aún hoy (aunque a veces en forma velada) mostrando serias reticencias a la profundización "integral" del Mercosur. Estamos pues ante un problema, en sí mismo original (de los orígenes) o fundante, que debe ser estudiado y explicado como tal, en vez de sólo analizar sus efectos "a posteriori".

Defender este enfoque analítico no supone negar que, "tal como hasta ahora ha operado", el Mercosur va teniendo una serie de efectos sobre los estados y actores involucrados, y que esos efectos pueden y deben también ser aislados y estudiados, constituyendo este "objeto" un campo legítimo para las ciencias sociales. Pero en todo caso, también estos "efectos" deben ser reincorporados en su acción de "feedback" al sistema de variables a tener en cuenta al analizar el desarrollo actual y los escenarios futuros que enfrenta el proceso de integración, en sus aspectos estructurales y en su incidencia sobre las posiciones que van tomando los diversos actores en presencia, algunos de ellos justamente "constituidos" 
en su operacionalidad (programática o instrumental) como efecto del proceso mercosuriano tal como se ha desarrollado hasta ahora.

¿Cómo negar, por ejemplo, que una vez lanzado y puesto en marcha el proceso de integración, muchos sectores involucrados han recogido (e integrado a su estrategia) el discurso oficial predominante, y que es desde esa lógica que plantean sus "nuevas" exigencias y también que demandan espacios para participar en las decisiones? No hay que pensar sólo en el incremento de participantes y reclamos corporativos en el espacio del Foro Consultivo Económico Social. Algo similar ocurre con el incremento de la demanda de mayor espacio político-constitucional desde la Comisión Parlamentaria, y en muchas otras subcomisiones técnicas que se han ido creando a influjo de la "movilización" generada desde 1990. Incluso mucho mas allá de las instancias formales del Mercosur en sentido estricto, hay que constatar y estudiar el impacto sobre el futuro del proceso del florecimiento de múltiples iniciativas y espacios de encuentro surgidos desde sectores sociales muy diversos ${ }^{5}$. Sectores de los cuales, más allá de sus especificidades corporativas o profesionales, interesa jerarquizar el hecho de que se reúnen invocando también su pertenencia al espacio Mercosur, y por lo tanto soslayando en las convocatorias a sus similares de otros países de América del Sur.

Es decir que con cierta independencia de la marcha "oficial" del Mercosur, lentamente se va constituyendo un nuevo espacio de pertenencia -a la vez simbólico y material- de los actores sociales. Este hecho puede verse a menudo -y no sin algo de razón- como puramente formal u "oportunista"; pero incluso en esos casos no deja de ir contribuyendo a la creación de un tejido que no preexistía, que de una u otra forma se incorpora a la nueva realidad emergente, y que como tal deberá ser tenido en cuenta cada vez más tanto por los decisores como por los analistas del proceso. Entenderlo y explicarlo requiere pues mucho más que detenerse sólo en los efectos de lo que ya existe.

Para evitar confusiones, cabe aquí decir claramente que nos parece indiscutible que, sin la existencia de condiciones de viabilidad que permitan consolidar y profundizar al menos los intercambios comerciales -y también sin duda las inversiones y ciertos sectores productivos-, no podrá tampoco continuar profundizándose el proceso mismo del Mercosur. Pero lo que queríamos señalar es que en cualquier hipótesis sobre el futuro, ya hay en las sociedades de cada país algo nuevo e irreversible que se ha puesto en marcha en ese espacio que en otros trabajos hemos llamado el "núcleo estratégico" de América del Sur ${ }^{6}$ (sin perjuicio de las eventuales nuevas incorporaciones). Que algo nuevo se haya puesto en marcha en "las sociedades" no garantiza, por supuesto, que el proceso ha de culminar necesariamente en una integración de la profundidad que fue adquiriendo la inicial Comunidad del Carbón y el Acero hasta llegar a la actual Unión Europea. Tampoco nos dice nada per se sobre el carácter más o menos democrático y equitativo de la futura sociedad del espacio mercosuriano. Pero sí nos dice que 
será difícil eliminar de aquí en más las presiones en ese sentido del activismo mercosuriano emergente en varios segmentos de la sociedad civil, y en grado quizás menor en ciertos sectores políticos. Y por lo tanto que es necesario incluir estos temas en las agendas de investigación sobre el Mercosur.

Otro aspecto significativo de cómo pensamos que se deben abordar los estudios del proceso mercosuriano es aquél que se refiere al nivel de agregación del objeto investigado. Es sin duda necesario e imprescindible que economistas, juristas y expertos en relaciones internacionales y geopolítica sigan aplicándose al tratamiento global del desempeño del bloque de países como tal, y sus relaciones con el "entorno" americano y mundial. Pero al mismo tiempo, si se quiere tener una visión más adecuada y por lo tanto más pertinente científica y políticamente, es imprescindible promover y jerarquizar la investigación desagregada no sólo de cada país, sino también de los procesos subregionales al menos en dos niveles. Por un lado, las enormes diferencias en el punto de partida -y su paulatino involucramiento- de los diferentes estados, regiones, provincias y departamentos (según corresponda en cada caso), que articulan la realidad de cada país en lo económico pero también en lo sociopolítico y cultural'; por otro lado, los variados procesos sociales y económicos subregionales determinados por las proximidades físico-fronterizas, que en buena medida preexistían, pero que desde el tratado de Asunción han visto florecer iniciativas que en parte renuevan viejos planteos, pero que también promueven maximizar las oportunidades "locales" abiertas por el tratado8.

Este nivel de análisis hace sin duda referencia a la necesidad de tematizar las "asimetrías" internas de base geoeconómica, y sus dimensiones socioculturales y también políticas. Pero su alcance es más amplio, ya que nos lleva a la necesidad de jerarquizar el estudio sistemático de todas las asimetrías intra e inter países. Asimetrías que tienen alta significación para evaluar los posibles costos y beneficios de cada país en el proceso de integración (los actuales y las eventuales incorporaciones $)^{9}$; y por lo tanto también para evaluar las chances de ampliación del Mercosur, y cuánto éste puede llegar a promover un desarrollo equilibrado y equitativo entre los países miembros y sus poblaciones. Entendemos que éste es un problema pertinente en sí mismo, pero mucho más cuando tenemos en cuenta la gran diferencia de tratamiento del tema de las asimetrías que existe -en la letra y en las decisiones adoptadas- entre los tratados mercosurianos y los equivalentes europeos o de América del Norte. Nada obliga a que los procesos de integración deban ser iguales, lo que sería por otra parte imposible; pero es indudable que las ciencias sociales deben al menos dar cuenta de las causas de un tratamiento tan desigual por parte de los procesos mencionados. Podría pensarse que este problema afecta sólo a los países "chicos" del Mercosur, pero en realidad hace a la lógica profunda del formato de integración, y por lo tanto afecta a todo el proceso y a todos los países cualquiera sea su tamaño ${ }^{10}$. 
Finalmente, queremos señalar que una correcta apreciación de la trayectoria del Mercosur, y su evolución futura, requiere incluir -desde sus comienzos hasta la actual coyuntura- un análisis específico de su interacción, dinámica, con los otros polos de concentración y/o integración existentes en el mundo y la región americana ${ }^{11}$. Se trata en buena medida del campo de las relaciones económicas y geopolíticas internacionales como nivel en sí mismo, pero no sólo. También ese análisis debe hacerse buscando desentrañar cómo esas relaciones de fuerzas se interiorizan en cada país -y lo hacen hacia el futuro- a nivel de las elites técnicas, políticas y empresariales con peso decisivo en la toma de decisiones. Esto refiere no sólo a estudios económicos o de ciencia política, sino también de orden cultural, ideológico y sociológico. Ni cada país ni cada región es un bloque monolítico, sino un campo de fuerzas sociales con determinantes estructurales en proceso de cambio, más o menos elástico según el nivel de análisis que se aborde.

Resumiendo: lo que sostenemos es que cada nivel de análisis que hemos venido reseñando debe referir a los otros -en algún momento- en forma sistemática y planificada, como el único antídoto a los "peligros" que se pueden detectar al recorrer la extensísima literatura "mercosuriana" hoy existente. Por un lado, los reduccionismos simplificadores, ya sean los de tipo economicista, geopolítico y juridicista, o aquellos que abordan el estudio del Mercosur sólo como dato preexistente y/o como un conjunto agregado y global. Y por otro la dispersión, muy pocas veces "sintetizada", de infinidad de estudios muy puntuales o sectoriales (por el tema o por su alcance territorial), que si bien son imprescindibles y útiles, a menudo consisten más en estudios sobre lo que sucede en tal o cual país o región del área mercosuriana, que propiamente en un análisis de cómo esos procesos o estructuras se han visto o pueden verse influidos $-\mathrm{y}$ a su vez influir- en el proceso de integración en cuanto tal.

Se trata, ni más ni menos, de ir constituyendo la especificidad y legitimidad científica de un nuevo objeto de estudio, y no conformarse con la simple agregación -o a veces redesignación lingüística "oportunista"- de estudios sobre lo que sucede en cada lugar de la por cierto enorme área geográfica que hoy abarca el Mercosur.

Como es fácil percibir, defender este punto de vista metodológico refiere no sólo al diseño del libro que hoy presentamos a los lectores, sino también en buena medida a un programa de investigación de largo aliento; programa que obviamente nos desborda y que esperamos sea total o parcialmente acompañado -y enriquecido- por muchos de los cientistas sociales, de la región y fuera de ella, que hoy día desarrollan trabajos de investigación sobre el tema Mercosur en alguna de sus múltiples dimensiones. 


\section{Notas}

1 Alfonsín, Menem dos períodos y De La Rua en Argentina; Sarney, Collor, Itamar Franco y Cardoso en Brasil; Sanguinetti, Lacalle, de nuevo Sanguinetti y Batlle en Uruguay; Rodríguez, Wasmosi, Cubas y González Macchi en Paraguay.

2 Por ejemplo del tipo del que hicieron F.H. Cardoso y E. Falleto en su muy conocido libro de 1968 "Desarrollo y Dependencia".

3 Lo que queremos decir es que omitir en los modelos de análisis este carácter "abierto" y en disputa del formato del Mercosur, lejos de ayudar, hace perder información relevante para el análisis científico. Los diversos proyectos de actores nacionales e internacionales (en tanto externos al espacio del estado-nación) forman parte del proceso mismo; y por lo tanto de su posible evolución y los efectos actuales y futuros sobre cada país y el propio Mercosur como un todo.

4 Es importante recordar que la literatura al respecto está dividida sobre la escala ideal de los nuevos espacios de producción e intercambio, división que no se ha superado por la relativamente reciente incorporación del concepto de "regionalismo abierto", que para muchos -sobre todo analistas y políticos del "primer mundo"- no deja de ser un subterfugio puramente proteccionista.

5 Asociaciones de productores rurales medianos y pequeños; centrales sindicales; colegios profesionales; universidades públicas y privadas; grupos feministas, étnicos y culturales; asociaciones deportivas; asociaciones nucleadas por los espacios fronterizos; dirigentes políticos y sectores políticos; productores y creadores culturales en cine, poesía, etc.; y muchos otros más que no es el caso enumerar en este lugar.

6 Ver en especial nuestro trabajo Dilemas del Mercosur frente al ALCA y la $U E$ en un mundo globalizado, ponencia presentada al Colloque International "Les relations Europe-Amérique Latine à l'heure de la mondialisation", Aix en Provence, CREALC, 29-30 septiembre de 2000.

7 Para una adecuada comprensión y pronóstico del proceso mercosuriano tal como lo hemos conceptualizado, no parece prudente soslayar las enormes diferencias internas que existen, por ejemplo, entre el Norte y el Sur-Sureste del Brasil; entre el Noreste y el Centro en Argentina; entre Montevideo y el Noreste uruguayos, y lo mismo puede decirse del Paraguay.

8 Es el caso especialmente de las fajas fronterizas "vivas" que comparten Uruguay y Argentina; Uruguay y Brasil; Argentina y Brasil; Argentina y Paraguay; Brasil y Paraguay, así como las dos triples fronteras existentes.

9 Si el tema de la "escala" de los países es siempre en sí mismo relevante, mucho más lo es en el caso del Mercosur dada la enorme asimetría física, de- 
mográfica y económica existente entre Brasil y el resto, muy especialmente con Uruguay y Paraguay. Ello no agota ni la lista ni el sentido cambiante de las asimetrías, ya que en otros ítems, por ejemplo el Uruguay, ocupa un "ranking" bastante por encima de sus vecinos.

10 Una experiencia empírica que abona a favor de este razonamiento es el propio devenir histórico de la integración europea. Si el acuerdo inicial franco-alemán evolucionó hacia las sucesivas y significativas ampliaciones que conocemos, no fue por una supuesta "obligación" -histórica u económicasino por una voluntad política y geopolítica de los países claves involucrados. Voluntad que -entre otros factores- fue posible concretar gracias al tratamiento explícito de las asimetrías y la puesta en práctica de los instrumentos jurídicos y económicos para suavizarlas.

11 No sólo conceptualmente -modelo de análisis-, sino por las mismas agendas de negociación ya en curso, sería erróneo estudiar los escenarios futuros del Mercosur sin ver su interacción con el NAFTA, la UE y la propuesta AL$\mathrm{CA}$; aunque también deben ser tenidas en cuenta las propuestas de Zona de Libre Comercio Sudamericana, y las negociaciones en curso con otros países asiáticos, africanos y de Oceanía. Más globalmente, es la propia disputa sobre el modelo mundial futuro (más o menos multipolar) lo que configura el marco general del análisis necesario. En todo caso, no se puede ignorar que la propuesta de ZLC americana estuvo y está enmarcada en esa disputa estratégica. 
